\title{
CONSUMER ACCEPTANCE OF OUTDOOR ADVERTISING: A STUDY OF THREE CITIES
}

\author{
Bianca BOŞTINĂ-BRATU \\ Action Belgium BVBA, Brussels, Belgium \\ bia2b@hotmail.com
}

Simona BOŞTINĂ-BRATU

"Nicolae Bălcescu" Land Forces Academy, Sibiu, Romania

mbostinabratu@yahoo.fr

Alina Gabriela NEGOESCU

"Nicolae Bălcescu" Land Forces Academy, Sibiu, Romania

alina.negoescu@yahoo.com

Lucia PALEA

“Nicolae Bălcescu” Land Forces Academy, Sibiu, Romania

lucia.palea@yahoo.com

\begin{abstract}
Advertising is a tricky business, which constantly becomes the subject of polemics and taboos. Opinions, whether positive or negative, tend to be very radical, and this can be noticed in the urban landscapes of certain metropolises around the world. The aim of this research is to analyze the nature, purpose, and consequences of outdoor advertising as perceived by the consumer side of the market. Therefore, the focus of the research in this paper is on the degree of acceptance, by consumers, of this communication medium, as well as on how it varies according to geographical location. The analytical methodology used to this effect involves the creation of a questionnaire aiming to collect micro-economic and psychographic data about consumers in three metropolises in different parts of the world. The conclusion of the research is that consumer perception of outdoor advertising is influenced by the geographical location, and its longevity depends on the way it will be carried out in the next few years.
\end{abstract}

KEYWORDS: advertising, billboards, consumer, acceptance, marketing

\section{Introduction}

"Advertising promotes that divine discontent which makes people strive to improve their economic status", says Ralph Starr Butler (2015), a great pioneer of the
Marketing discipline. Indeed, advertising develops the taste for novelty, encourages freedom and creativity, educates the public, and keeps the economy turning (Zukin and Maguire, 2004). It also influences people 
emotionally (Moore and Harris, 1996) and urges them to take actions (Huntington, 2009). Considered as the oldest form of advertising, (Shimp and Andrews, 2013) outdoor advertising is the center of many polemics around the world, and its true value for society is often questioned. Previous findings suggest that content in an advertisement significantly increases attention, benefits memory, and positively influences people's behavior (Dahl, Frankenberger and Manchanda, 2004). When does it stop being a friendly communication tool and start becoming a polluting enemy for the environment? Should billboards be fined, restricted, sizeregulated, or outright banned? Do consumers still acknowledge the utility of this medium of communication?

Consistent with prior research dedicated to demonstrating the effects and consumer perception of advertising (e.g., Gardner, 1985; MacKenzie, Lutz, \& Belch 1986; McKenzie, \& Lutz, 1989, Taylor, Franke \& Bang, 2006), our study investigates the nature, purpose, and consequences of this communication medium as perceived by the consumer side of the market.

\section{Methodology}

The aim of this paper, part of a larger and more exhaustive research study, is to analyze the way in which outdoor advertising is perceived in three different locations around the world. For this purpose, the three cities chosen were São Paulo, economic capital of Brazil, Bucharest, capital city of Romania, and Brussels, capital city of Belgium and of Europe. These particular cities were chosen for their striking differences, but also for their unique characteristics that make them good study material. Three sub-samples of population were created, one for each city. Each sub-sample represents only a small part of each population, and it is used to deduce common characteristics of that specific population. The appropriate number of respondents that is necessary for each sample depends first and foremost on the raison d'être of the research, as well as its objectives, because the size of the samples must be in accordance with the degree of precision aimed. In the case of outdoor advertising, the goal of the questionnaire is to paint a general picture of the likes and dislikes of citizens of each city concerning billboards, in order to come upon possible patterns and preferences. Consequently, precision is only of secondary importance in this research. Therefore, we can admit a rather high error margin, as opinions and tastes are difficult to quantify. The error margin for all three samples is approximately $10.5 \%$, meaning that the results are not significantly off, in $89,5 \%$ of the cases. Moreover, it is compensated by the use of appropriate statistical tests. With this in mind, the appropriate size $\mathrm{N}$ of all the samples reunited can be calculated, using a statistical formula, where $\mathrm{N}$ represents the total number of respondents necessary for all the samples:

$$
\begin{gathered}
\mathrm{N}=1 / 0.105^{2}=1 / 0.011025 \\
\mathbf{N}=\mathbf{9 0}
\end{gathered}
$$

As the error margin of $10.5 \%$ was considered appropriate, it results that the total number of respondents necessary for this experiment is of minimum 90 individuals. Since one sample is made for each of the three cities, this number divided by 3 gives an idea of the size that each sample should have, in this case a minimum of 30 respondents for each city. The sample size is evidently smaller than the population, so there is no need to apply any kind of correction factor.

In order to avoid discrepancies in the results as much as possible, it is important to consider the incidence rate among the respondents. That is, certain individuals could distort the pool of answers obtained in a specific city, if they are not, in fact, 
residents, but tourists. To avoid this trap, certain filters were scattered all over the questionnaire, in order to facilitate the elimination of such respondents. The Brazilian city is a very ethnically diverse metropolis, comprising of 111 different ethnic groups. Its history of international immigration, which intensified during the 19th and 20th centuries, led people of various origins such as European, Arab, Asian, African, Jewish, Latin American, or North American to settle there. Although these people are not originally from São Paulo, they have usually lived there (Associação Brasileira de Estudos Populacionais (ABEP), 2015) for many years and thus can have a very useful take on things. The same is valid for Belgium, where the threshold of one million foreigners living in the country was reached in 2008 (DeMayer, 2011). Moreover, $30 \%$ of the Brussels Region population is made of foreigners, not to mention those that are not declared at all. As for Bucharest, it hosts almost one-third of a total of 109,814 foreign nationals who have their residence in Romania in the first quarter of 2016, according to the General Inspectorate for Immigration (Popescu, 2016), most of them coming from countries outside the European Union such as Moldova, Turkey, and China.

Another factor to keep in mind so as to avoid discrepancies and distortions of results is the refusal rate. Since not every individual that was randomly selected to participate to the questionnaire accepted, it would be ideal to attempt to estimate the proportion of refusals. A person may refuse to participate to such a research in order to avoid having to give personal details, or because he or she is embarrassed by his or her views and fears to be judged. It is safe to assume that around $30 \%$ of all the individuals invited to take the questionnaire refused. This means that the number of people who should be asked to participate to this study must be around 120 if we want to make sure that, in the end, 30 answers per city are obtained. In fact, after having finished collecting the questionnaires of all 90 individuals required, we realized that a larger number of respondents would have been superfluous, not to mention too much time-consuming for the purpose and the extent of this research. Indeed, a certain theoretical saturation was reached, as most people gave similar answers, suggesting clear trends and tendencies (Bostina-Bratu, 2012).

Now that the population and the sample size are clearly defined, the practical exercise of actually choosing individuals to invite to answer the questionnaire is described. Considering that the population of each city can be defined with precision, this means that individuals had an equal chance to be chosen for this survey. Even though we began to spread the questionnaire amongst people of different ages and backgrounds that we knew, we firmly believe that our sample should not be considered a non-probabilistic one, as we used the snowball sampling method. Even though the participating respondents did so voluntarily, this is a good guarantee of the fact that they understood what was asked of them, and answered out of interest and not out of obligation.

\subsection{Research Concept}

The reason different cities from different parts of the world have been chosen to study is that, in the authors' opinion, advertisements represent a mirror of the cultural behaviors of a country or a part of the globe. Different perspectives are expected to be encountered, from South America, more precisely São Paulo, Brazil, a developing market, where social inequalities are very present, and people have already experienced a ban on outdoor advertising, to Bucharest, Romania in formerly communist Eastern Europe, and to Brussels, Belgium in Western Europe, where capitalism is predominant and the 
consumption society is in its prime. São Paulo, one of the world's largest metropolises, was one of the pioneers in the revolution against public advertising. In 2006, the city's populist right-wing mayor, Gilberto Kassab, passed the "Clean City Law", or "Lei Cidade Limpa" (Plummer, 2006), that started to apply on January 1st 2007. This was the beginning of a prohibition of all types of billboards in the Brazilian economic capital. One of the main arguments put forward was the visual pollution caused by posters for political campaigns. Any kind of billboard is currently forbidden in São Paulo, from the traditional $4 \times 3 \mathrm{~m}$ to advertisements in taxis and buses, even electronic displays and flyers distribution (Tinar, 2010).

In Bucharest, Romania, the market seems eager to encourage outdoor advertising as a way of promoting capitalism, the freedom of speech and of choice, and to boost consumerism as well. According to a GfK Omnibus Survey conducted in Bucharest, in 2010, by the market research Institute GfK Romania, a quarter of Romanians living in the capital notice and read billboards on their way to and from work daily, particularly those with average and higher education. In an interview with the International Advertising Association Romania in April 2012, CEO Eliza Rogalski of the market research company Tempo Team clearly stated the importance of a consumer focus in the Romanian advertising business (Rogalski, 2012). The company also conducted a study which they named 'Consumer Advocacy Radar' in order to determine which type of media was most trusted by the Romanian population. After discovering that the most important influence is actually that of family, friends, and internet forums, marketers decided it was time to bring outdoor advertising to new levels. Gigantic billboards were thus installed all over the city, on the façade of shopping malls, on rooftops, and on apartment buildings. As a recent evolution, one can notice the led video displays that use advanced technology to render the displays waterproof, sun-screen, antistatic, damp proof, anti-freeze, and anti-thundering. Needless to say, Romania is one of those countries where outdoor advertising is on a role, with a bright and promising future ahead (Romania-Insider, 2015).

Brussels, Belgium, provides interesting results due to its unique mixture of demographics and the importance it gives to freedom of expression. According to an article published by the Belgian newspaper 'L'Echo' (Sacré, 2012), Belgium is a country with a rather stable evolution in the advertising market. It is a good example of a city that is very meticulous with its outdoor billboards. Advertising companies offer their clients the possibility to place billboards in various positions and at various angles, like flat against the wall, or with the edges folded over an aluminum frame for a more polished finish, to create more depth and a more solid fixing. For advertising campaigns that are intended to be changed regularly, color printed wraps are commonly used. Moreover, the most prevalent forms of outdoor advertising after billboards are street furniture, transit and alternative forms (AllBusiness Editors, 2009) which will very briefly be reviewed:

\subsection{Research Sample}

The population out of which the sample respondents were chosen was defined according to a regional approach, namely the entire population of each of these cities, suburbia included. Despite the fact that the population of each city is recorded annually, and consequently easily retrieved, its size is so big that it can be considered as an infinite population from a statistical point of view. Three sub-samples were created, one for each city. Each subsample represented only a small part of each population, and it was used to deduce 
common characteristics of that specific population. The appropriate number of respondents necessary for each sample depended first and foremost on the "raison d'être" of the research, as well as on its objectives, because the size of the samples had been in accordance with the degree of precision aimed. In the case of outdoor advertising, the goal of the questionnaire was to paint a general picture of the likes and dislikes of citizens of each city concerning billboards, in order to come upon possible patterns and preferences. Consequently, precision was only of secondary importance in this research. Therefore, a rather high error margin is admitted, as opinions and tastes are difficult to quantify. The error margin for all three samples is approximately $10.5 \%$, meaning that the results are not significantly off, in $89.5 \%$ of the cases. Moreover, it is compensated by the use of appropriate statistical tests.

After determining whether they agreed to participate, a number of 30 consumers, randomly selected for each location were sent, via e-mail, a questionnaire composed of three parts, in order to evaluate their opinions on the topic. Why use e-mail and social networks instead of a face to face interview, or a telephone survey? The reason behind this choice was two-fold.

Firstly, this seemed to be the optimal method to obtain truthful and clear answers in a timely, non-costly fashion. Secondly, and most importantly, the aim of this study was to obtain the honest opinion of individuals from three places with very different cultural backgrounds. A face to face interview would have certainly allowed some interaction with the individual at the moment a question was asked, making it possible to react to the answer and maybe even ask secondary questions to complete or clarify it. Nevertheless, this kind of interaction would not have been optimal in the case of a research of such a varied public. Indeed, a language barrier may have appeared, due to the fact that each chosen city has its own national language(s). A Romanian person may have been a lot more reticent than a Belgian one in answering such complex questions in another language than his or her mother tongue, or simply incapable of doing so, as Bucharest is a much less cosmopolite city than Brussels. This argument applies to São Paulo as well as, despite the varied demographics, composed of immigrants from various places of the world, Portuguese remains the most spoken language in the city, so the chances of an individual speaking fluent English are much lower there. The same problem can be invoked for telephone interviews, where the language barrier would be amplified due to possible (Williams, 2008) reception or network problems. Moreover, by telephone, people can easily decide against participating to the survey, or simply against answering the telephone.

The written questionnaire allowed the interviewer to put her language skills to good use by translating the questions from English to the necessary local languages. This way, respondents had a better chance of understanding the purpose of each question and could express themselves clearly, in the language of their choice. As a transmission channel, the e-mail and social networks, especially Twitter and Facebook, were used as the majority of people in the three cities are familiar with the Internet and use it extensively. Thus, social networks were used to reach the younger portion of the population, while e-mail was used to reach the more adult or senior segment, that do not (often) use social networks. Additionally, according to the Direct Marketing Association, e-mail produces among the highest response rates, at $2.45 \%$ for direct marketing media channels (Green, 2008). 


\section{Questionnaire}

The questionnaire conceived to find out more about consumer preferences related to outdoor advertising was composed of three main parts. In the first part, some personal data is required in order to get to know the respondent better. The questions were short and to the subject, usually requiring a digit, a yes/no answer, or a one-word answer. Thus, these can be considered as nominal variables, as any statistical or mathematical value cannot be attributed to them. The data contained by these variables was used in order to determine the possible link between personal information and the general view of billboards.

\subsection{Part 1 of the Questionnaire:} Nominal Variables \& Treatment

Firstly, they were asked to provide some basic information about their sociocultural background, in order to determine the micro-economic factors that are considered influential for the main question of the survey. It is interesting to notice that, among the personal data required, there are some dichotomist variables. One such variable is the ownership of a personal vehicle, which can only take two values: yes or no. Another such variable is the place where the respondent lives, which, in this context, allows only for two possible answers: city or suburbia. The purpose of this brief analysis was to verify the null hypothesis that there is a relationship between the independent variable of owning a personal vehicle and the dependent variable of the acceptance of outdoor advertising.

It resulted that people avoid owning a private vehicle as, for the total sample of 90 respondents, only 39 own a car, compared to that do not. This may be due to several reasons, ranging from the recent precarious economic conjuncture, to the raising concerns with pollution leading to climate change and global warming. Nevertheless, there are also regional explanations. In São Paulo, the traffic is the most intense out of all the three cities, and the city is by far the biggest, both in area and in number of inhabitants (CIA, 2012). Bucharest is also a very crowded city, but inhabitants still prefer to use cars, a behavior which might be due partly to the rather precarious condition of the public transportation system, and partly to culturally-induced tendencies (such as the fact that owning a car puts the individual on a higher social level, as a car is a noticeable good that one can parade around). In Brussels, on the other hand, public transportation is heavily used both by people living in the city and by those living a bit further away Here, inhabitants seem more interested to avoid pollution than people in other cities. Consequently, a slight majority of those that do not own a personal car appears.

\subsection{Part 2 of the Questionnaire:} Complex Nominal Variables \& Treatment

The second part of the questionnaire focused on consumers' personal views of billboards. They were asked to detail how they perceived billboards in general, whether they were pro or against outdoor advertising, and whether their view varied according to the type or the location of billboards. All these questions were based on a concrete, visual support in the form of photos attached to the questionnaire. Some of these photos were identical for all consumers in all locations, thus serving as a common reference for all respondents, while other photos were specific to each location. The answers obtained here are mostly under the form of one or more phrases, including more detailed information about the respondent's opinions and feelings concerning billboards in the city. The answers are considered to be complex nominal variables, and must be interpreted theoretically, in an attempt to set light on certain patterns of behavior or of thought. The general consensus of 
respondents in all three cities was that, while outdoor advertising can contribute to the embellishment of the city by bringing color and information, as well as by occupying dead time while waiting for the bus or metro, this type of media can easily become intrusive and even manipulative. It often crosses the barrier of too much advertising. Billboards placed in certain places in the city are especially frowned upon, such as big-sized posters on the side of apartment buildings, in historical sites, or on rooftops. Overall, it seems as though Paulistas need a little more time before they are ready to receive outdoor advertising back into their city and their lives. Romanians, on the other hand, seem generally happy with the way the advertising industry is evolving in the country, although a few changes and innovations are needed if the industry is to be taken more seriously by consumers. In Brussels, consumers are currently fed up with outdoor advertisement, so major changes would need to be applied in this industry for it to be appreciated. Indeed, advertising is too seldom considered as an art, although its conception requires a lot of imagination, creativity, and uniqueness from the part of marketers, making it a rather artistic discipline. More specifically, people realize the utility of outdoor advertisements not necessarily because one could not live without them, but because they contribute to the wellbeing and growth of the economy.

\subsection{Part 1 of the Questionnaire: Ordinal Variables \& Treatment}

The third part of the survey had in view psychographic factors, determined with the help of a Likert scale going from 1 to 5. At the very end, a general question to conclude their position relative to outdoor advertising was asked, specifically whether or not they believed it should be restricted or banned, and for what reasons. The analysis of the answers showed that in São Paulo, the general feeling towards outdoor advertising was just starting to improve, after several years of total banishment of billboards. Nevertheless, those that are still against this form of advertising are a majority. In Bucharest, the people in favor of outdoor advertising clearly overtake those against it, with a ratio of 19:11. This could be explained by the eagerness of people to enjoy a wide range of choices of products and services. In Brussels, the general opinion is towards the acceptance or indifference of outdoor advertising, with a ratio of $22: 8$ in favor. This may be because outdoor advertisement in Brussels is well regulated, and many of the billboards appearing in the city are advertising cultural events such as music concerts, theatre plays, movies, or sports events. Therefore, people feel more at ease with this sort of advertising, and also appreciate the funny and colorful ads that distract them while waiting for their bus or metro.

\section{Discussion}

In this paper, some examples of consumer acceptance of billboards were discussed, from radical São Paulo to balanced Brussels. The influential emerging market of São Paulo, Brazil, presents unique characteristics that make the research very interesting. The huge income gaps and the absence of a middle class, in parallel with the stability of this metropolis from a financial and economic point of view, have rendered it an interesting subject (Turow and McAllister, 2009). especially due to its rather extravagant decision to ban all outdoor advertising a few years ago, when the number of ads plastered over the whole city became overwhelming for the citizens, who felt they were just being manipulated and pressured into buying. According to recent polls, 70 per cent of the population in São Paulo still wants to keep the city ad-free. Bucharest, Romania, this Eastern European location, liberated from communist constraints and limitations, has become very capitalist in the last 25 years, maybe aiming to get as far away as possible from the extreme left regime they were 
stuck under for many years. Brussels, Belgium, situated in the heart of Western Europe, this small capital city with dense but ageing population, with a stable income level, where people tend to be jaded, is used to billboards and taking them for granted.

To sum up the findings, it is safe to say that people generally would not opt for the option of completely banning outdoor advertising, which is good news for the advertising industry. Also, the kind of billboard and its purpose are very important in the eyes of consumers. A general acceptance for billboards used to cover up construction or renovation sites in the city is expressed, and billboards in stations seem to have an entertaining effect. At the same time, many are those that are concerned with the fact that billboards represent (visual) pollution. Answers to the last statement should also be of some concern for the advertising industry. If people do not consider advertising as an art and do not allow themselves to be seduced by it, that means that advertising is becoming less creative, and should improve this aspect in order to gain popularity.

The results obtained with the help of the questionnaire and the statistical tools all point towards one evident fact: outdoor advertising is not dead, nor is it being dwarfed by the novelties of the $21 \mathrm{st}$ century. Its perception varies according to the geographical location, and its longevity depends on the way it will be carried out in the next few years. Indeed, it is clear that for consumers, less is more when it comes to billboards in the city. According to results of the present experiment, outdoor advertising is seen as a means to fill an empty moment by many consumers, as they claim to only passively notice ads.

\section{Conclusions}

"Sanely applied advertising could remake the world"- economist Stuart Chase (1956) expressed in a few words what this paper has been trying to demonstrate. Outdoor advertising is the oldest means of communication with the masses, and yet it has managed to survive until today thanks to its great adaptation power. In this new era of technology and digitalization, outdoors has managed to adapt and earn its place as one of the most used means of advertising. Granted, its methods are highly controversial, and range from being widely exploited to generate revenue and fame, to being completely rejected and banned.

The dependence between city and consumer opinions of billboards is the main finding of our research. The implications to global marketing can be substantial once this result is confirmed and studied in more detail. Indeed, this outcome suggests that regional, and even niche marketing, is by far more productive than a more general, global approach. Outdoor should be more regulated and more supervised, and it should fit the culture and the expectations not only of each country, but even of each big city. Advances have been made in that sense, with the advent of mobile digital and modal marketing for instance, that adapts the message of billboards according to the location or the mood of the passers-by.

To conclude, we are living in a period of change, with new technology, social and demographic trends all pushing to modify our view of the world. Outdoor is a very visible medium that confers brands a presence on the street, in the reality of the consumer, but for this it must be renewed constantly. It costs nothing to the individuals, and it offers both value for time and money, by using dead time. In this respect, outdoor is an optimal medium for the modern consumer, as long as it is well integrated and adapted to each city's urban landscape. It should be in harmony with nature, and always tidy and organized. Despite the budget, time, and credibility limitations of this work, new research paths could be exploited, on how outdoor advertising could adapt to the culture and personality of each specific metropolis. 


\section{REFERENCES}

AllBusiness Editors. (2009). Using Outdoor Advertising to get Exposure for your Business, Advertising, Marketing \& PR, available at: http://www.allbusiness.com/marketingadvertising/marketing-advertising/11817449-1.html, accessed on: 25.03.2017.

Associação Brasileira de Estudos Populacionais (ABEP). (2015). available at http://www.abep.org.br/site/index.php/grupos-de-trabalho/populacao-e-historia/ementa accessed on: 02.04.2017.

Boştină-Bratu, B. (2012). Consumer Acceptance of Outdoor Advertising: A Study of Three Cities, Mémoire présenté en vue de l'obtention du Master en Sciences économiques, finalité en Management Sciences, Solvay Brussels School Economic \& Management.

Butler, R. S. (2015). Marketing Methods, Sagwan Press.

Central Intelligence Agency (CIA). (2017). The World Factbook, available at: https://www.cia.gov/library/publications/the-world-factbook/, accessed on: 25.03.2017.

Chase, S. (1956). The proper study of mankind, 2nd Ed., New York: Harper \& Brothers.

Dahl, D. W., Frankenberger, K. D., \& Manchanda, R. V. (2004). Does It Pay to Shock? Reactions to Shocking and Non-shocking Advertising Content among University Students, Journal of Advertising Research, 43, 268-280.

DeMaeyer, Ph. (2011). Rapport national Belgique 2007-2011 à l'attention de l'Association Cartographique Internationale (ACI), available at: https://icaci.org /files/documents/national_reports/2007-2011/Belgium.pdf, accessed on: 16.08.2017.

Gardner, M. P. (1985). Does Attitude Toward the Ad Affect Brand Attitude Under a Brand Evaluation Set?, Journal of Marketing Research, 22(2), 192-198.

Green, L. (2008). Sales and Marketing that Work. How to Grow a Business by Putting People First, Amherst, Massachusetts: HRD Press, Inc.

Huntington, R. (2009). Shock ads are about more than getting headlines, New Media Age, 10(8), 5-6.

MacKenzie, S. B., \& Lutz, R. J. (1989). An Empirical Examination of the Structural Antecedents of Attitude toward the Ad in an Advertising Pretesting Context, Journal of Marketing, 53(2), 48-65.

MacKenzie, S. B., Lutz, R. J., \& Belch, G. E. (1986). The Role of Attitude toward the Ad as a Mediator of Advertising Effectiveness: A Test of Competing Explanations, Journal of Marketing Research, 23(2), 130-143.

Moore, D. J., Harris, W. (1996). Affect Intensity and the Consumer's Attitude toward High Impact Emotional Advertizing Appeals, Journal of Advertizing, 25(2), 37-50.

Plummer, R. (2006). Brazil's ad men face billboard ban, available at: http://news.bbc.co.uk/2/hi/business/5355692.stm, accessed on: 25.03.2017.

Popescu, I. (2016). How many foreigners live in Romania?, available at: http://www.romania-insider.com/how-many-foreigners-live-in-romania/, accessed on: 25.02.2017.

Rogalski, E. (2012). Advocacy-ul este cea mai pură şi sustenabilă formă de creare a reputaţiei, available at: http://www.iaa.ro/Articole/Interviuri/Eliza-rogalski-advocacy-ul-estecea-mai-pura-si-sustenabila-forma-de-creare-a-reputatiei/4982.html, accessed on: 25.03.2017.

Romania-Insider.com. (2015). Investments in outdoor advertising, up by $6 \%$ in Romania, available at: http://www.romania-insider.com/investments-outdoor-advertising-upromania/ 153350/, accessed on: 02.12.2017. 
Sacré, J. F. (2012). Faible croissance pour le marché publicitaire belge en 2011, available at: https://www.lecho.be/tech-media/media-marketing/Faible-croissance-pour-lemarche-publicitaire-belge-en-2011/9157336?utm campaign=nextarticle, accessed on: 25.06.2017.

Shimp, T. A., \& Andrews, J. C. (2013). Advertising Promotion and Other Aspects of Integrated Marketing Communications, Cengage Learning.

Taylor, C. R., Franke, G. R., \& Bang, H. K. (2006). Use and Effectiveness of Billboards: Perspectives from Selective-Perception Theory and Retail-Gravity Models, Journal of Advertising, 35(4), 21-34.

Tinar, S. (2010). Electoral Pollution Afflicts Cities, available at: http://riotimesonline.com/brazil-news/rio-politics/electoral-pollution-afflicts-cities/, accessed on: 02.12.2016.

Turow, J., \& McAllister, M. (2009). The Advertising and Consumer Culture Reader, New York and London: Routledge.

Williams, R. (2008). Advertising, the magic system. Problems in Materialism and Culture. London: Verso, 170-195.

Zukin, S., \& Maguire, J. S. (2004). Consumers and Consumption, Annual Review of Sociology, 30, 173-197. 